\title{
ADDITIVE EDGE BINDING LAYERS TO SUPPRESS FREE-EDGE DELAMINATION UNDER TENSILE LOAD
}

\author{
Miguel Ubago Torres $^{1 *}$, Meisam Jalalvand ${ }^{2}$ \\ ${ }^{1}$ Advance Composites Group (ACG), Department of Mechanical and Aerospace Enginnering, \\ University of Strathclyde, Glasgow, United Kingdom \\ ${ }^{2}$ Engineering Materials, Department of Mechanical Engineering, University of Southampton, \\ Southampton, UK \\ *miguel.ubago-torres@strath.ac.uk
}

An additive laminate applied to the free-edges of cured composite laminates was used for stopping delamination in laminates under tension. The solution was examined on an angle-ply substrate laminate (AP laminate) susceptible to delamination with a layup of $\left[\left(20_{2} /-20_{2}\right)\right]_{s}$. Numerical analyses were conducted to determine the effectiveness of this technique and the experimental results proved that the free-edge delamination was successfully suppressed.

A Python code for Abaqus 2019 was developed for calculating the interlaminar energy release rate $(\mathrm{G})$ values for a range of pre-crack lengths at different interfaces of the AP laminate, when no binding was applied. The slice model technique proposed in [1], and represented in Figure 1 , was used to achieve high accuracy while reducing computation weight. The interface with higher $\mathrm{G}$ values was determined to be the most probable to delaminate (critical interface).

The additive binding layup selected was $[ \pm 45]_{s}$. Figure 2 shows a comparison of the $\mathrm{G}$ values at the critical interface for both cases with and without binding. The $\mathrm{G}$ was reduced by $70 \%$. Experimentally, the tensile failure strain and load of the laminate were increased by about $50 \%$. Thus, this technique suppresses delamination successfully.

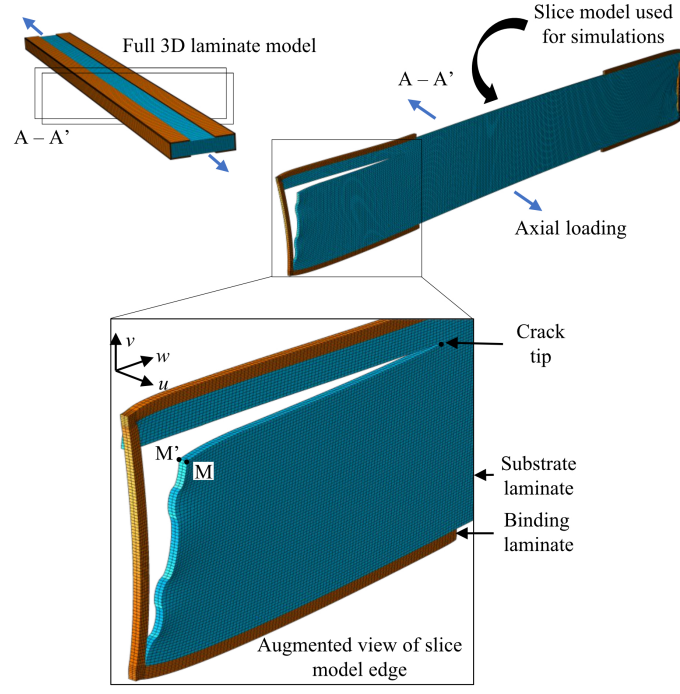

Figure 1: Slice model used with binding applied.

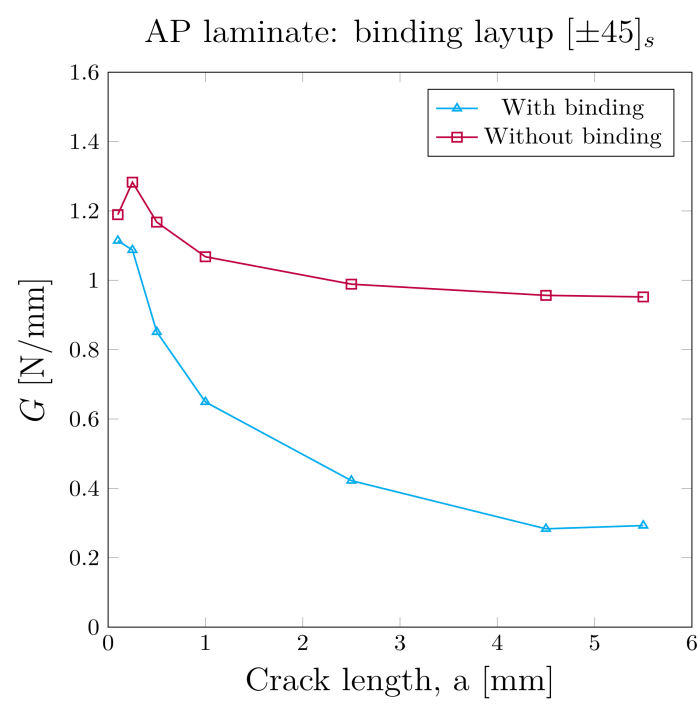

Figure 2: G versus crack length for AP laminate at the critical interface.

\section{References}

[1] W.G. Jiang, J.L. Henshall (2006) Analysis of composite laminate beams using coupling cross-section finite element method. Applied Mathematics and Mechanics, 27, 1709-1718. 